\section{Dried Bay Leaf: An Unusual Cause of Upper Gastrointestinal Tract Hemorrhage}

Acute hemorrhage from the upper gastrointestinal tract is one of the most frequent emergency situations encountered in gastroenterology. The most frequent causes of hemorrhage are complications due to peptic ulcer disease. In extremely rare cases, profuse hemorrhage is caused by foreign bodies in the upper digestive tract (1). Most often, foreign bodies stray into the digestive tract inadvertently during food intake (2).

A 76-year-old woman was admitted to the Department of Internal Medicine due to hemorrhage from the gastrointestinal tract. She mentioned that about a week earlier she had eaten a large bite of pressed sausage containing a large bay leaf. After swallowing it, she had long fits of coughing which subsided on the same day. The initial clinical examination revealed nothing abnormal. A rectal examination confirmed hemorrhage from the gastrointestinal tract, since abundant traces of melenic feces were evident. The hemogram showed marked anemia, with erythrocyte values of $2.10 \times 10^{12} / 1$ and hemoglobin values of $70 \mathrm{~g} / \mathrm{l}$. Emergency endoscopy was carried out with the Olympus GIF-Q30 endoscope (Olympus Ltd., Hamburg), detecting the bay leaf, which had become lodged between the opposite duodenal walls. Using a biopsy forceps, the author pulled the leaf into the stomach (Figure 1), and then carried out endoscopic hemostasis of the bleeding ulcer (Forrest IB) in the duodenal bulb. The ulcer had developed at the point at which the leaf's stem had been stuck in the wall. After hemostasis, the $45 \times 25 \mathrm{~mm}$ leaf was entirely removed from the stomach using an alligator-jaw GIF-FB-15 forceps (Olympus Ltd., Hamburg) (Figure 2). After a control endoscopic investigation, the patient was discharged on the twelfth day of treatment.

Foreign bodies in the upper gastrointestinal tract rarely cause hemorrhage. Various types of foreign body can be involved: parts of kitchen utensils, needles, wire, razor blades, coins, batteries, buttons, toothbrushes, safety pins, and many more $(3-5)$. In older people, the foreign bodies may also be dentures or other unintentionally swallowed objects or bites of food (2). Other foreign bodies found in the upper digestive tract are bezoars (trichobezoar, phytobezoar), and balls of different constituents forming around foreign bodies in the stomach (3). In the patient described here, the lodgment of a dried bay leaf in the duodenal bulbs resulted in inflammation and the development of an acute ulcer with hemorrhage. The endoscopic procedure itself made it possible to carry out endoscopic hemostasis of the bleeding ulcer and remove the foreign body.

\section{P. Skok}

Dept. of Gastroenterology and Endoscopy, Maribor Teaching Hospital, Ljubljanska, Maribor, Slovenia

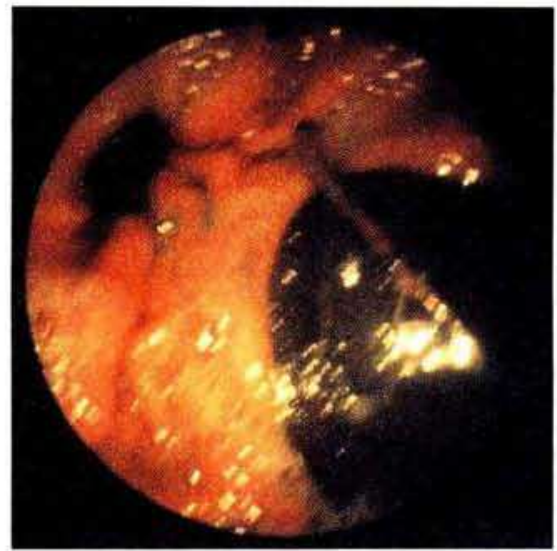

Figure 1: The bay leaf under the pylorus.

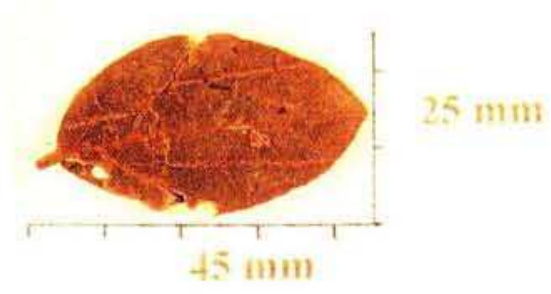

Figure 2: The $45 \times 35 \mathrm{~mm}$ bay leaf after its removal from the stomach.

\section{References}

1. Velitchkov NG, Grigorov GI, Losanoff JE, Kjossev KT. Ingested foreign bodies of the gastrointestinal tract: retrospective analysis of 542 cases. World J Surg 1996; 20: 1001-5. 


\section{Unusual Cases and Technical Notes \$41}

2. Hyman FN, Klontz KC, Tollefson L. Food and Drug Administration surveillance of the role of foreign objects in foodborne injuries. Public Health Rep 1993; 108: 54-9.

3. Witzel L. Fremdkörper. In: Hahn RG, Riemann JF. editors. Klinische Gastroenterologie. Stuttgart: Thieme, 1996: 656-9.
4. Stack LB, Munter DW. Foreign bodies in the gastrointestinal tract. Emerg Med Clin North Am 1996; 14: 493521.

5. Quinn PG, Connors PJ. The role of upper gastrointestinal endoscopy in foreign body removal. Gastrointest Endosc Clin North Am 1994; 4: 571-93.
Corresponding Author

P. Skok, M.D.

Dept. of Gastroenterology and Endoscopy

Maribor Teaching Hospital

Ljubljanska 5

2000 Maribor

Slovenia

Fax: + 386-62-511388 